\title{
CBT plus parental anxiety management was more effective when the child and parent(s) were anxious
}

\author{
Cobham VE, Dadds MR, Spence SH. The role of parental anxiety in the treatment of childhood anxiety.J Consult Clin Psychol 1998 \\ Dec;66:893-905.
}

\section{Question}

In children with anxiety disorder, is child focused cognitive behavioural therapy (CBT) with parental anxiety management (PAM) more effective than child focused CBT alone?

\section{Design}

Randomised, single blind (outcome interviewers), controlled trial stratified by parental anxiety with 12 months follow up.

\section{Setting}

Child and Adolescent Anxiety Project at the University of Queensland, Australia.

\section{Patients}

67 children (mean age $10 \mathrm{y}, 51 \%$ boys) who had anxiety disorder (separation anxiety disorder $[\mathrm{n}=8]$, overanxious disorder $[\mathrm{n}=3]$, generalised anxiety disorder $[n=40]$, simple phobia $[n=12]$, social phobia $[n=3]$, or agoraphobia $[n=1])$ and their families were recruited from referrals from parents, mental health professionals, and teachers. Exclusion criteria were concurrent nonanxiety diagnosis with a severity level of $\geqslant 4$, significant medical problems, or physical or intellectual impairment.

\section{Intervention}

The families were assigned to CBT alone ( $\mathrm{n}=17$ child anxiety only, $\mathrm{n}=18$ child and parental anxiety) or CBT plus PAM $(\mathrm{n}=15$ child anxiety only, $\mathrm{n}=17$ child and parental anxiety). CBT consisted of 10 weekly sessions and was based on the Coping Cat programme. PAM consisted of 4 sessions and helped to make the parents aware of their role in their children's difficulties and to make them aware of their own anxiety responses.

\section{Main outcome measure}

Proportion of children still meeting the criteria for an anxiety disorder with a clinical severity rating of $\geqslant 4$ on a telephone version of the Anxiety Disorders Interview Schedule.

\begin{abstract}
Main results
Children whose parents reported high levels of anxiety responded less well to treatment than did children whose parents were free of anxiety symptoms after treatment $(81 \% v$ $57 \%, \mathrm{p}<0.05)$. At post-treatment and within the child anxiety only condition, $82 \%$ of the children in the CBT group no longer met criteria for an anxiety disorder compared with $80 \%$ in the CBT plus PAM group $\{\mathrm{p}=0.9\}^{*}$. Within the child and parental anxiety condition, $39 \%$ in the CBT group no longer met criteria compared with $77 \%$ in the CT plus PAM group $\{p=0.03\}^{*}$ (table). At 12 months the differences between treatment conditions were no longer statistically significant $(77 \%$ of the children in the child anxiety only condition were diagnosis free $v 65 \%$ in the child plus parental anxiety condition, $\left.\{\mathrm{p}=0.3\}^{*}\right)$.
\end{abstract}

\section{Conclusions}

At post-treatment, CBT plus PAM was more effective than CBT alone in children with one or more anxious parents. This benefit was not present when only the child was anxious and the beneficial effect was no longer evident at 12 months of follow up.

*p value calculated from data in article.

Rates of no longer having an anxiety disorder after treatment $\dagger$

\begin{tabular}{lllll}
\hline Condition & CBT plus PAM & CBT & RBI (95\% CI) & NNT (CI) \\
\hline $\begin{array}{l}\text { Child and parental } \\
\text { anxiety condition }\end{array}$ & $77 \%$ & $39 \%$ & $97 \%(9$ to 291$)$ & $3(2$ to 21$)$
\end{tabular}

$\lceil\mathrm{CBT}=$ cognitive behavioural therapy; PAM = parental anxiety management; other abbreviations defined in glossary; RBI, NNT, and CI calculated from data in article.

Source of funding: National Health and Medical Research Council.

For correspondence:Dr VE Cobham, School of Psychology, University of Queensland, St Lucia, 4072 Queensland, Australia. Fax +61 733654466.

\section{Commentary}

The role of family psychopathology in the genesis and maintenance of anxiety disorders in children and adolescents is often asserted but less often documented. ${ }^{1}$ At the patient level, the necessity of including treatment for parents depends on an analysis of parental psychopathology and its association to problem behaviours in the child. ${ }^{2}$ Even when family or parental psychopathology is present, the inclusion of parent or family interventions is clinically necessary only if parent or family problems would otherwise reduce the effect size of child directed interventions. Effective interventions with graded or no family involvement have been shown for obsessive compulsive disorder and posttraumatic stress disorder, respectively. ${ }^{34}$ Conversely, the addition of a parent inter- vention has been shown to increase the effectiveness of intervention for childhood anxiety problems more than child treatment alone. ${ }^{5}$

In this important study, Cobham et al show that this effect occurs primarily in those families with anxious parents who are overly involved in their children's symptoms. Interestingly, low anxiety parents who did not need the intervention did not drop out or do worse with treatment, suggesting that a brief parent intervention is well tolerated even in those families who presumably do not need it. Although various methodological weaknesses (small sample size, parent only interview for the main outcome measures, and the lack of demonstrable effects across child anxiety measures) somewhat weaken the overall conclusion, this study suggests that clinicians treating anxious children will be well advised to include parent interventions for those parents whose own anxiety seems to contribute to the maintenance of anxiety in their children.

John March, MD, MPH Duke University,

Durham, North Carolina, USA

1 Wells K. Family therapy. In: March J, editor. Anxiety disorders in children and adolescents. New Anxiety disorders in children and adoles

2 Rapee RM. Clin Psychol Rev 1997;17:47-67.

3 March JS, Mulle K, Herbel B. J Am Acad Child Adolesc Psychiatry 1994;33:333-41.

4 March JS, Amaya-Jackson L, Murray MC, et al.J Am Acad Child Adolesc Psychiatry 1998:37:58593.

5 Barrett PM, Dadds MR, Rapee RM. J Consult Clin Psychol 1996;64:333-42. 